\title{
Electrospun Polylactide/Natural Rubber Fibers: Effect Natural Rubber Content on Fiber Morphology and Properties
}

\author{
Yulia Tertyshnaya ${ }^{1,2, *}$ C , Svetlana Karpova ${ }^{1}$, Maksim Moskovskiy ${ }^{2}$ and Aleksey Dorokhov ${ }^{2}$ \\ 1 Department of Biological and Chemical Physics of Polymers, Emanuel Institute of Biochemical Physics, \\ Russian Academy of Sciences, 4 Kosygina Str., 119334 Moscow, Russia; karpova@sky.chph.ras.ru \\ 2 Federal Scientific Agroengineering Center VIM, 1st Institutskiy Proezd, 5, 109428 Moscow, Russia; \\ maxmoskovsky74@yandex.ru (M.M.); vim@vim.ru (A.D.) \\ * Correspondence: terj@rambler.ru; Tel.: +7-495-939-71-86
}

Citation: Tertyshnaya, Y.; Karpova, S.; Moskovskiy, M.; Dorokhov, A. Electrospun Polylactide/Natural Rubber Fibers: Effect Natural Rubber Content on Fiber Morphology and Properties. Polymers 2021, 13, 2232. https://doi.org/10.3390/ polym13142232

Academic Editor: Edith Perret

Received: 26 April 2021

Accepted: 5 July 2021

Published: 7 July 2021

Publisher's Note: MDPI stays neutral with regard to jurisdictional claims in published maps and institutional affiliations.

Copyright: (C) 2021 by the authors. Licensee MDPI, Basel, Switzerland. This article is an open access article distributed under the terms and conditions of the Creative Commons Attribution (CC BY) license (https:// creativecommons.org/licenses/by/ $4.0 /)$.

\begin{abstract}
Non-woven polylactide-natural rubber fiber materials with a rubber content of 5, 10 and $15 \mathrm{wt}$ \% were obtained by electrospinning. The thermal, dynamic, and mechanical properties of the fibers were determined. It was shown that the average fiber diameter increased with adding of the NR content, while the linear and surface densities changed slightly. Using the differential scanning calorimetry, the thermal characteristics were obtained. It was found that the glass transition temperature of polylactide increased by $2-5{ }^{\circ} \mathrm{C}$, and the melting temperature increased by $2-4{ }^{\circ} \mathrm{C}$ in the presence of natural rubber in the samples. By the method of electronic paramagnetic resonance at $\mathrm{T}=50$ and $70{ }^{\circ} \mathrm{C}$ it was determined that the mobility of the amorphous phase in PLA/NR fibers increased with the addition of NR. The adding of NR at a content of $15 \mathrm{wt} . \%$ increased the value of elongation at break by 3.5 times compared to pure PLA.
\end{abstract}

Keywords: polymer fibers; polylactide; natural rubber; non-woven fiber; electrospinning; interfacial interactions; crystalline phase; physical properties

\section{Introduction}

In recent decades, the state of the environmental situation has led to the introduction of "green" polymers and composites based on them in various industries [1-3]. Film and fiber materials based on various polymers are finding new applications in medicine and the agricultural sector [4-6].

In this work, samples of non-woven fiber material were obtained by electrospinning. On the one hand, electrospinning is an economical, efficient, and versatile method for manufacturing fiber materials with nano- and submicron fiber diameters [7-9]. On the other hand, it is a complex process involving the hydrodynamics of weakly conducting Newtonian liquids and phase transformations-The evaporation of the solvent and the removal of the polymer fiber.

Non-woven mats obtained by electrospinning have a high porosity, small pore size and a good interconnected pore structure, which facilitate the transport of air molecules and the capture of particles $[10,11]$. Based on these characteristics, many types of nonwoven fiber membranes were manufactured and studied [12-14]. Modern trends in the development of innovative fiber are focused on non-toxic, eco-friendly materials [15,16]. The use of a thermoplastic biodegradable polymer-polylactide (PLA) obtained from plantbased renewable raw materials, in large-scale production has become possible due to the properties of PLA, which can serve as the basis for materials that are competitive with composites based on polyolefins and synthetic polyesters $[17,18]$. At the same time, the use of PLA for the creation of fiber and film composite materials reduces the dependence on oil [19].

The production and properties of non-woven fibers from PLA and PLA composites are described in [20-22]. Casasola and coauthors studied the effect of solvent and solvent 
mixtures on the morphology and diameter of PLA nanofibers. As a result, it was found that the boiling point, conductivity, and viscosity of the solvent affect the process of forming fibers, their structure, and properties [20]. Earlier work by Jun (2003) also showed the influence of the solvent on the process of electrospinning polylactide fibers, on the morphology and diameter of the elementary fiber [21]. The authors [22] obtained and studied non-woven PLA/PHB fibers and determined their antimicrobial ability. Intensive growth of Chaetomium globosum and Aspergillus niger was detected on untreated PLA/PHB fibers, which was quite expected since Aspergillus niger is one of the most aggressive micromycetes [23].

Despite a significant number of articles on the morphology, thermal and mechanical properties, degradation of non-woven PLA fibers and composites based on it [24-26], there are no reports of the production and properties of non-woven fiber PLA/NR besides the work [27]. There are some papers that investigate the blends of PLA/NR obtained by dynamic vulcanization [28] or PLA/ENR [29], PLA/NBR [30], PLA/NR prepared by a melt mixer [31].

This work is devoted to obtaining and studying the morphology and properties of nonwoven PLA-NR fibers. Natural rubber is an elastomer obtained from a renewable source of raw materials, from rubber tree juice. NR combines biocompatibility, biodegradability, and environmental friendliness. Addition of NR to the PLA matrix will improve the elasticity of the polylactide and produce a bio-material.

\section{Materials and Methods}

\subsection{Sample Preparation}

Poly(lactic acid) PLA, 4032D (with about $2 \%$ of D-lactide) with molecular weight $\left(\mathrm{M}_{\mathrm{w}}\right)$ of $1.7 \times 10^{5} \mathrm{~g} / \mathrm{mol}$ and $\varrho=1.24 \mathrm{~g} / \mathrm{cm}^{3}$ was procured from Nature Works (Minnetonka, MN, USA) and used without any purification. Natural rubber (NR), SVR-3L with Mooney viscosity $50 \pm 5\left(100{ }^{\circ} \mathrm{C}\right)$ and poly(cis-1,4-isoprene) content: 91-96, wt.\% was kindly supplied by Vietnam Rubber Group (Ho Chi Minh City, Vietnam).

The polymer solutions for electrospinning were prepared by dissolving PLA and $\mathrm{PLA} / \mathrm{NR}$ in the right ratio in $100 \mathrm{~mL}$ of chloroform. The mixtures were heated at $60{ }^{\circ} \mathrm{C}$ for about 4-5 min. The polymer solution was placed in a syringe with a needle inner diameter $0.7 \mathrm{~mm}$, set up vertically. The electrospinning experiments were performed at room temperature $\left(20 \pm 2{ }^{\circ} \mathrm{C}\right)$. The consumption of the solution was $(9-11) \times 10^{-5} \mathrm{~g} / \mathrm{s}$. The sample weight was $9 \mathrm{~g}$ per $100 \mathrm{~mL}$ and the ratio of the components (PLA:NR, wt.\%) was 100:0, 95:5, 90:10 and 85:15. The electrospinning process was run for at least $5 \mathrm{~h}$ with a voltage of $17.5-19 \mathrm{kV}$, a distance of $17 \pm 1 \mathrm{~cm}$ between the needle tip and the collector until a non-woven fiber was produced. Five fiber samples were prepared for each solution.

\subsection{Analysis of Crystallization}

Thermal analysis was performed by differential scanning calorimeter (DSC) using a DSC 204 F1 device (Netzsch, Selb, Germany) under a nitrogen atmosphere. Samples of about 5.0-5.4 mg sealed in aluminum pans were heated from room temperature to $200^{\circ} \mathrm{C}$ at rate of $10{ }^{\circ} \mathrm{C} / \mathrm{min}$. Indium with $\mathrm{T}_{\mathrm{m}}=156.6^{\circ} \mathrm{C}$ was used as a calibrant. The crystallinity of PLA $\left(\chi_{\mathcal{c}}\right)$ was estimated from the first heating cycle using the following Equation (1):

$$
\chi_{\mathrm{c}}(\%)=100 \% \times\left(\Delta H_{\mathrm{m}} / \Delta H_{\mathrm{m}}{ }^{*}\right)
$$

where $\Delta H_{\mathrm{m}}$ is the enthalpy of melting during heating, $\Delta H_{\mathrm{m}}{ }^{*}$ is the enthalpy assuming $100 \%$ crystalline PLA homopolymer $93.1 \mathrm{~J} / \mathrm{g}$ [1].

\subsection{Determination of Mechanical Characteristics}

Mechanical characteristics were determined according to ISO 527-4: 2012 by tensile compression testing machine Devotrans DVT GP UG 5 (Istanbul, Turkey). The tensile strength, elongation at break, and modulus of elasticity were determined. The crosshead velocity was $0.5 \mathrm{~mm} / \mathrm{min}$. The data was averaged by seven samples. 


\subsection{Fiber Structural Characteristics and Morphology}

The structural characteristics of the fiber samples were determined according GOST 15902.2-2003 (ISO 9073-2:1995): Nonwoven fabrics. Methods of determination of structural characteristics.

The morphology of electrospun PLA and PLA/NR fibers was characterized by scanning electron microscopy Philips SEM-500 (Eindhoven, The Netherlands).

\subsection{Electronic Paramagnetic Resonance}

The molecular mobility was studied by the spin probe method on an EPR-V automated EPR spectrometer (Semenov Federal Research Center For Chemical Physics, Russian Academy of Sciences, Moscow). The stable nitroxide 2,2,6,6-tetramethylpiperidine-1-oxyl was used as a probe. The radical was introduced from vapors in the films at $40{ }^{\circ} \mathrm{C}$ to a concentration of up to $10^{-3} \mathrm{M}$. The EPR spectra were recorded in the absence of saturation, which was checked according to the dependence of the signal intensity on the microwave field power. The probe rotation correlation time $\left(\tau_{c}\right)$ was calculated from the EPR spectra according to the Equation (2) [24]:

$$
\tau_{\mathrm{c}}=\Delta \mathrm{H}_{+} \times\left[\left(\mathrm{I}_{+} / \mathrm{I}_{-}\right)^{0.5}-1\right] \times 6.65 \times 10^{-10}
$$

where $\Delta \mathrm{H}_{+}$is the width of the low-field component of the spectrum, and $\mathrm{I}_{+} / \mathrm{I}_{-}$is the intensity ratio of low- to high-field components, respectively.

\subsection{FTIR Spectroscopy}

The IR spectra were recorded on a Perkin Elmer Spectrum 100 FTIR spectrometer (USA) at temperature $(22 \pm 2)^{\circ} \mathrm{C}$.

\subsection{Statistical Processing}

The experimental results were calculated as the arithmetic mean and its standard error. The calculations were performed using Statistica 8.0 software (Dell Software Inc., Round Rock, TX, USA) and Microsoft Excel 2007.

\section{Results}

\subsection{Morphology and Structural Characteristics}

Non-woven fiber materials, PLA/NR with the different contents of NR in the spinning solution, were obtained by electrospinning. Figure 1 shows the scanning electron micrographs of the PLA and PLA/NR samples.

The obtained composites are heterophasic and while forming and evaporating the solvent the system stays in a non-equilibrium state, which leads to the appearance of different fiber thicknesses (Figure 1b-d). With an increase in a NR content in the PLA matrix, the fiber structure tends to bead-string morphology. The difference in the viscosity of PLA and NR also affects the formation of beads. So, the dynamic viscosity of the PLA is $0.52-0.54 \mathrm{~Pa} \cdot \mathrm{s}$, and those of PLA/NR containing $10 \mathrm{wt} . \%$ of NR is 1.4 times higher.

Important characteristics of fiber materials are linear and surface density, as well as the average diameter $\left(d_{a v}\right)$ of the fiber. A large role is played by the solvent. There are works that show the effect of the solvent on the formation of non-woven fibers [20,21]. In the case of a two- or more-component system, the process of selecting a solvent becomes more complicated. Both PLA and NR are well dissolved in chloroform, and the chloroform evaporates quickly enough to allow the fibers to harden until they reach the collector, but not too quickly to allow maximum pulling of the fibers until they harden. The average diameter of the fiber (Table 1) increases with the addition of NR to the PLA matrix, but the linear and surface density change slightly, so when the NR content is $15 \mathrm{wt} . \%$ the linear and surface density values increase by $3 \%$, which is within the error range. 


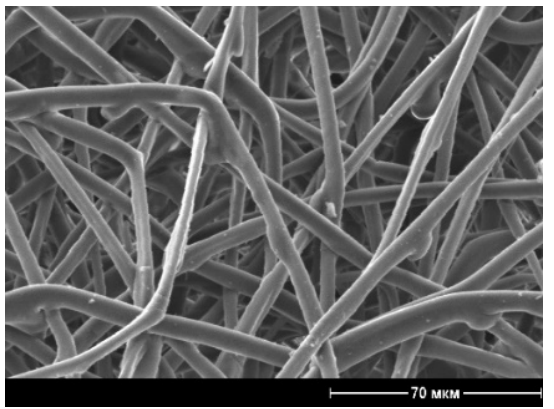

(a)

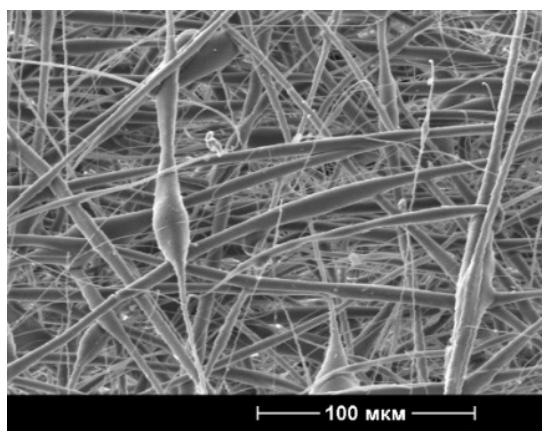

(c)

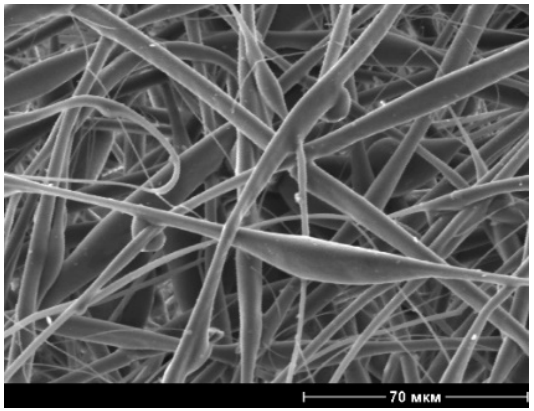

(b)

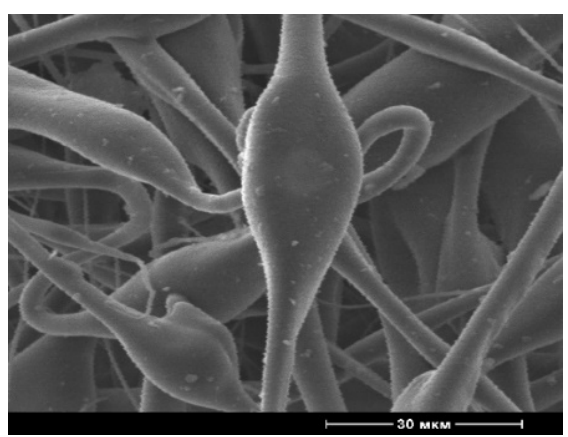

(d)

Figure 1. Scanning electron micrographs of PLA (a) PLA/NR fibers with 5 wt.\% (b) 10 wt.\% (c) and 15 wt. $\%$ (d) of NR content.

Table 1. Structural characteristics of PLA/NR non-woven fibers.

\begin{tabular}{cccc}
\hline NR, wt. $\%$ & \multicolumn{3}{c}{ Structural Characteristics } \\
\hline & $\boldsymbol{d}_{\boldsymbol{a v}}, \boldsymbol{\mu \mathbf { m }}$ & Linear Density, $\mathbf{g} / \mathbf{m}$ & Surface Density, $\mathbf{g} / \mathbf{m}^{\mathbf{2}}$ \\
\hline 0 & $5.84-7.20$ & $0.950 \pm 0.023$ & $47.5 \pm 0.89$ \\
5 & $6.24-8.22$ & $0.963 \pm 0.018$ & $48.2 \pm 1.16$ \\
10 & $6.51-8.81$ & $0.955 \pm 0.015$ & $47.0 \pm 1.03$ \\
15 & $6.64-9.24$ & $0.977 \pm 0.021$ & $49.1 \pm 1.20$ \\
\hline
\end{tabular}

\subsection{DSC Data}

The method of differential scanning calorimetry was used to determine the thermophysical characteristics of PLA/NR non-woven fibers. Melting thermograms are shown in Figure 2. One can see that the adding of NR into the PLA matrix changes the temperature of the phase transitions: $T_{\mathrm{g}}, \mathrm{T}_{\mathrm{cc}}$ and $\mathrm{T}_{\mathrm{m}}$ of the thermoplastic.

Numerical data is shown in Table 2. Thus, the glass transition temperature $\left(\mathrm{T}_{\mathrm{g}}\right)$ of PLA increases by $2-5^{\circ} \mathrm{C}$ with an increase in the content of NR in the spinning solution. A similar relationship is observed for the melting temperature, the degree of crystallinity $\left(x_{c}\right)$ of the PLA changes by $2-4 \%$, and the crystallization temperature has an increasing trend. The change in the $\mathrm{T}_{\mathrm{g}}$ of the polylactide may be a consequence of a change in the supramolecular structure, and the influence of differences in the thermal expansion coefficients of the mixed components is not excluded [32]. The small changes in $\mathrm{T}_{\mathrm{m}}$ can be attributed to possible reorganization in the crystalline phase during heating. In the process of cold crystallization, the completion of crystallites probably occurs, and natural rubber facilitates the process of PLA crystallization. 


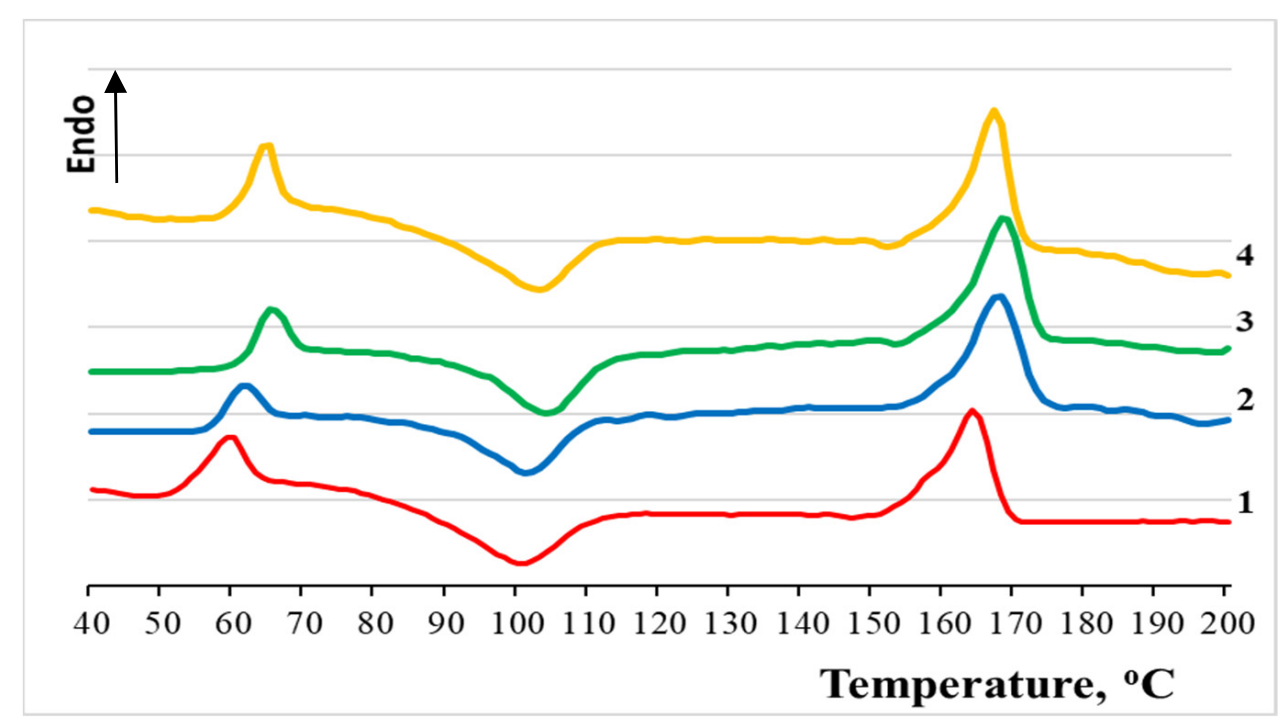

Figure 2. Melting thermograms of PLA/NR fibers. The content of NR, wt.\%: (1) 0; (2) 5; (3) 10; (4) 15.

Table 2. Thermophysical characteristics of PLA/NR non-woven fiber.

\begin{tabular}{ccccc}
\hline NR, WT.\% & \multicolumn{5}{c}{ Thermophysical Characteristics } \\
\hline & $\begin{array}{c}\mathbf{T}_{\mathbf{g}},{ }^{\circ} \mathbf{C} \\
\left(\boldsymbol{\Delta} \pm \mathbf{0 . 5}{ }^{\circ} \mathbf{C}\right)\end{array}$ & $\begin{array}{c}\mathbf{T}_{\mathbf{m}},{ }^{\circ} \mathbf{C} \\
\left(\boldsymbol{\Delta} \pm \mathbf{0 . 5}{ }^{\circ} \mathbf{C}\right)\end{array}$ & $\begin{array}{c}\mathbf{T}_{\mathbf{c c},},{ }^{\circ} \mathbf{C} \\
(\boldsymbol{\Delta} \pm \mathbf{0 . 5} \%)\end{array}$ & $\begin{array}{c}\chi_{\mathbf{c}}, \% \\
(\boldsymbol{\Delta} \pm \mathbf{1 \%})\end{array}$ \\
\hline 0 & 61 & 164 & 101 & 34 \\
5 & 63 & 168 & 102 & 36 \\
10 & 66 & 167 & 104 & 38 \\
15 & 65 & 166 & 104 & 37 \\
\hline
\end{tabular}

It is important to note that Chi [31] and coauthors obtained a similar result with respect to the degree of crystallinity in the mixed compositions obtained from the melt, and scientists from Thailand [33] found a significant increase in the degree of crystallinity of PLA with an NR content of 10-30 wt.\% in mixtures obtained from the melt.

\subsection{FTIR Spectroscopy}

IR-spectra of pure NR and PLA/NR (with $15 \mathrm{wt} . \%$ NR content) and pure PLA and PLA/NR (with $15 \mathrm{wt} . \%$ NR content) are shown in Figure $3 \mathrm{a}, \mathrm{b}$ respectively. The spectra of all fiber samples are identical. For clarity, the PLA/NR spectrum with an NR content of $15 \mathrm{wt} . \%$ is shown.

Comparing the spectra of pure polymers and PLA/NR, it can be seen that on the PLA/NR spectrum bands appear in the area of $1660-1640 \mathrm{~cm}^{-1}$ and $1550-1520 \mathrm{~cm}^{-1}$ (the small insert in Figure 3b). These bands correspond to the valence vibrations of $\mathrm{C}=\mathrm{C}-$ groups in natural rubber [34]. Also on the spectra of pure PLA and pure NR there is a band of $755 \mathrm{~cm}^{-1}$. In the PLA spectrum, it refers to stretching vibrations of $-\mathrm{C}-\mathrm{C}-$ bonds in the polylactide [35]. In the PLA/NR spectrum the intensity of this band increases. It means that the NR contributes to the intensity of this band. Thus, the structure of the polylactide changes with the addition of NR, which affects the thermophysical characteristics (Table 2), as well as the dynamic and mechanical properties that are presented below. 


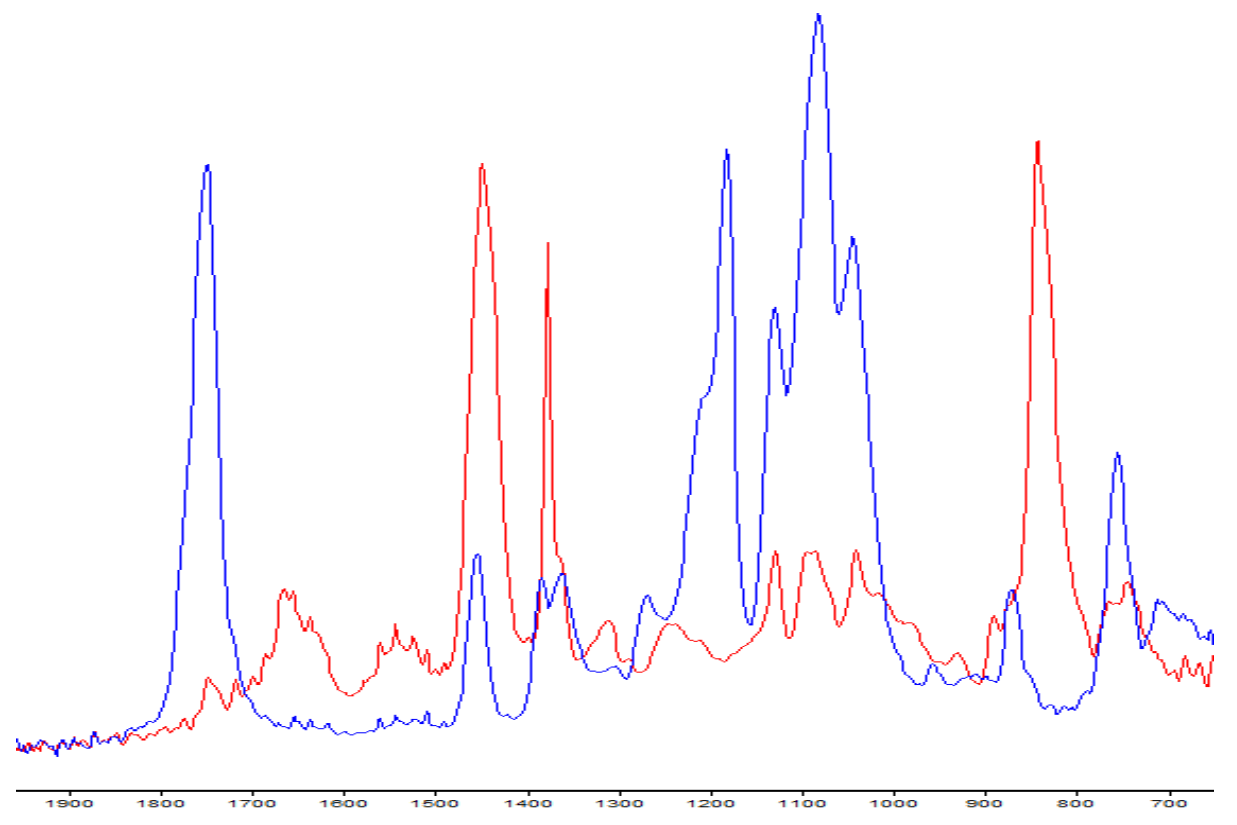

Wave length, $\mathrm{cm}^{-1}$

(a)

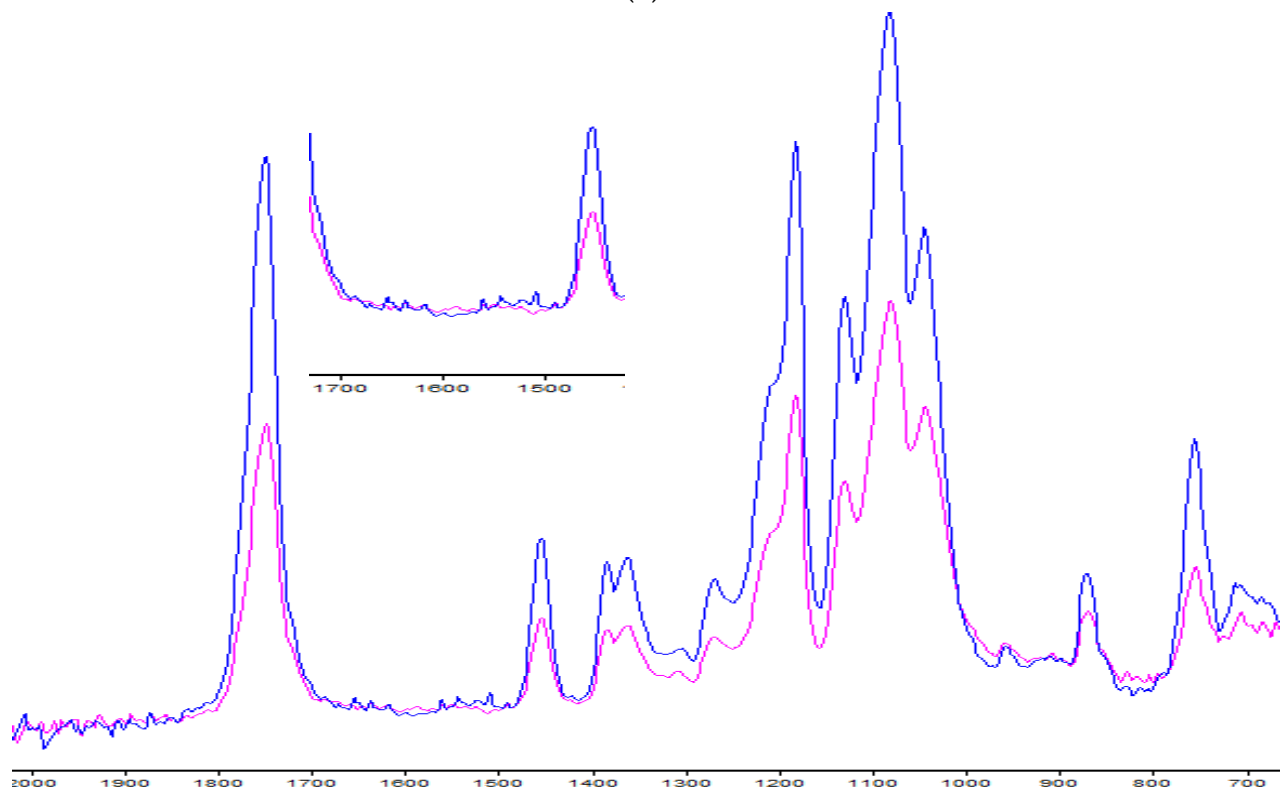

Wave length, $\mathrm{cm}^{-1}$

(b)

Figure 3. (a). IR-spectra of pure NR (red) and PLA/NR with 15 wt.\% NR content (blue). (b). IR-spectra of pure PLA (pink) and PLA/NR (blue) with 15 wt.\% NR content (blue).

\subsection{Nishi-Wang Equation}

From the DSC data, it follows that during electrospinning from a solution, NR affects the structure formation of the PLA. The effect of the amorphous component of the mixture on the PLA melting temperature can be analyzed based on the Nishi-Wang Equation (3) [36].

$$
\mathrm{T}_{\mathrm{m}} / \mathrm{T}_{\mathrm{m}}{ }^{*}=1+\mathrm{B}\left(v_{2} / \Delta H_{\mathrm{m}}{ }^{*}\right) \times \varphi_{2}{ }^{2}
$$

where $\mathrm{B}=\delta_{12} \mathrm{RT} / v_{2}$ at $\mathrm{T}=\mathrm{T}_{\mathrm{m}}$ - -melting point of $100 \%$ PLA, measured under the same heating conditions as for mixtures; $v_{1}$ and $v_{2}$-molar volumes of PLA and NR, respectively; 
$\Delta H_{\mathrm{m}}{ }^{*}$-heat of melting of $100 \%$ PLA crystal; $\delta_{12}$-compatibility parameter; $\varphi_{2}$ —volume fraction of NR; R-universal gas constant.

In the work, the compositions were measured under the same scanning conditions without determining the equilibrium values of the $T_{m}$. According to Equation (1), the dependence of $T_{m} / T_{m}{ }^{*}$ on $\varphi_{2}$ is shown in Figure 4 .

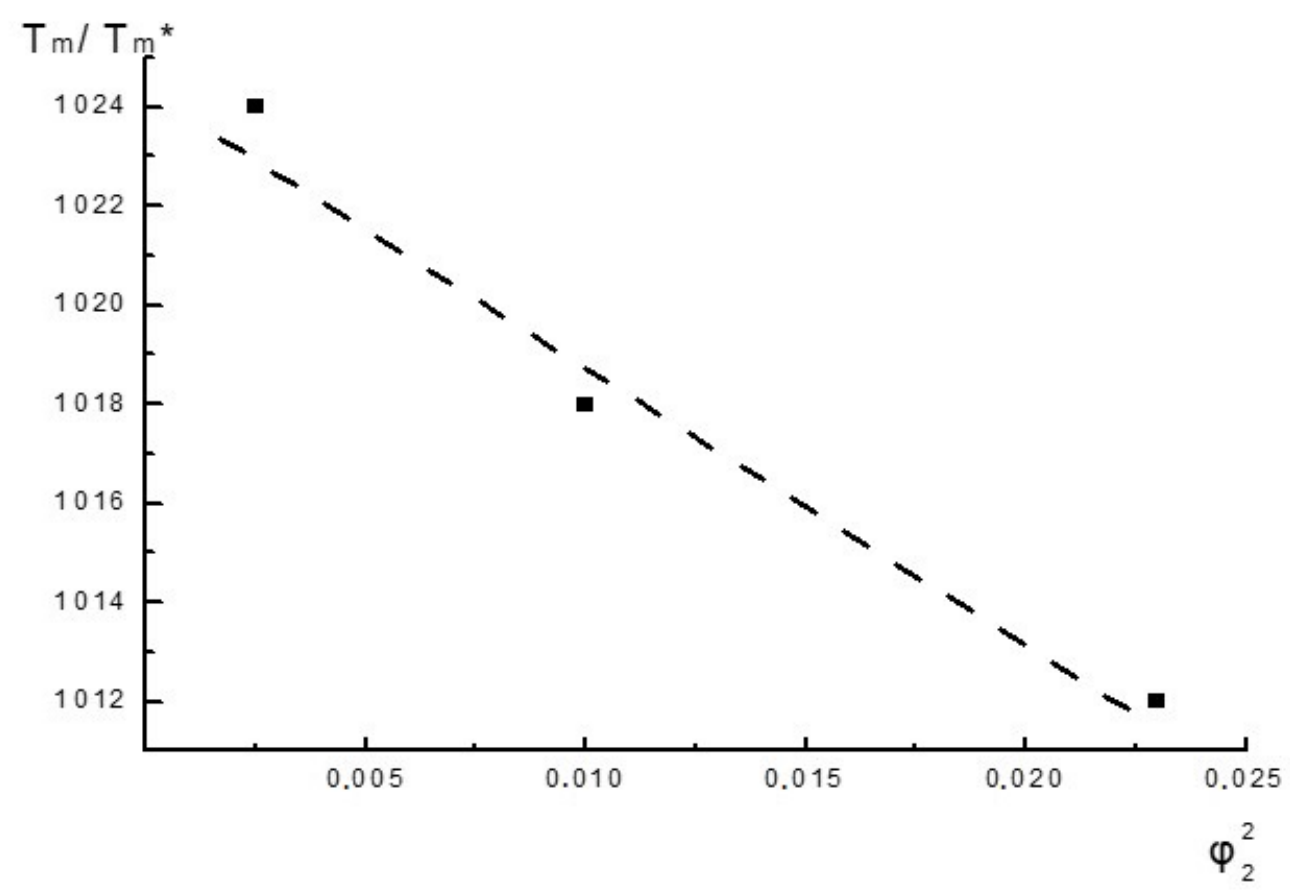

Figure 4. The Nishi-Wang parameter for PLA/NR fibers.

This dependence is of a qualitative nature, but the change in $T_{m} / T_{m}{ }^{*}$ is actually described by Equation (1). The Parameter $B$, and therefore $\delta_{12}$ are negative, which indicates some limited interaction at the level of the PLA and NR segments, which is probably the reason why there are changes in different characteristics.

\subsection{Macromolecules' Dynamic}

The EPR method was used to estimate the macromolecular mobility of the amorphous phase in fiber composites. The radical probe was introduced at two temperatures, at $\mathrm{T}=50^{\circ} \mathrm{C}$, when the PLA is in a glassy state, and above the PLA glass transition temperature-at $70^{\circ} \mathrm{C}$ (Figure 5).

Data is presented in Table 3. One can see that at $50{ }^{\circ} \mathrm{C}$, the correlation time $\left(\tau_{\mathrm{c}}\right)$ in PLA-NR samples is slightly lower than at $70{ }^{\circ} \mathrm{C}$. Changes in the obtained values are small, since the correlation time at $50{ }^{\circ} \mathrm{C}$ is determined by the prevailing phase, and the PLA is in a glassy state and the mobility of macromolecule segments is small, despite the presence of an amorphous component-natural rubber.

If the probe is inserted at $70^{\circ} \mathrm{C}$, a different situation can be observed. Above the glass transition, the segments of the PLA matrix are more mobile, in addition, the increase in the proportion of the amorphous phase due to NR at this temperature is more evident. Also according to the IR spectra, the amount of the amorphous phase increases. In composites, in comparison with PLA, segmental mobility increases by 3.5-4 times. The results obtained by the EPR method are in agreement with the DSC data: the degree of PLA crystallinity increases in the presence of NR due to a raising in segmental mobility and, apparently, easier stacking of PLA chains in crystallites. 


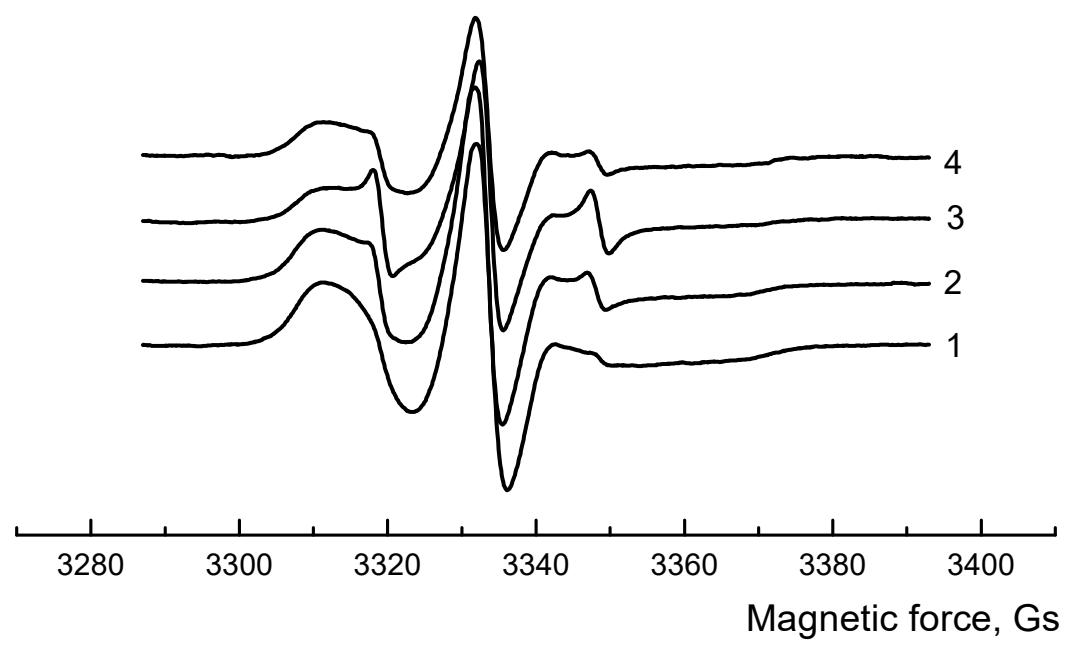

Figure 5. EPR spectra of PLA/NR fibers. The content of NR, wt.\%: (1) 0; (2) 5; (3) 10; (4) 15. The radical was inserted at $70^{\circ} \mathrm{C}$.

Table 3. The correlation time of the probe in PLA/NR fibers. The radical was inserted at $\mathrm{T}=50{ }^{\circ} \mathrm{C}$ and $\mathrm{T}=70^{\circ} \mathrm{C}$.

\begin{tabular}{ccc}
\hline NR, wt. $\%$ & \multicolumn{2}{c}{ The Correlation Time } \\
\hline & $\boldsymbol{\tau}_{\mathbf{c}} \times \mathbf{1 0}^{-\mathbf{1 0}} \mathbf{c}^{-\mathbf{1}}$, & $\boldsymbol{\tau}_{\mathbf{c}} \times \mathbf{1 0}^{-\mathbf{1 0}} \mathbf{c}^{-\mathbf{1}}$, \\
$\mathbf{5 0}^{\circ} \mathbf{C}$ & $\mathbf{7 0}^{\circ} \mathbf{C}$ \\
\hline 0 & $4.7 \pm 0.15$ & $62.0 \pm 0.23$ \\
5 & $3.8 \pm 0.11$ & $16.7 \pm 0.20$ \\
10 & $3.3 \pm 0.12$ & $17.8 \pm 0.18$ \\
15 & $2.9 \pm 0.18$ & $15.6 \pm 0.15$ \\
\hline
\end{tabular}

\subsection{Mechnical Properties}

All questions related to the crystallization and morphology of a polymer or polymer composite ultimately affect the mechanical properties. The mechanical characteristics of non-woven fibers are shown in Figure 6. It is shown that with an increase in the content of rubber in the molding solution, the relative elongation at the break of the obtained fibrous materials increases (Figure 6a). With a content of $15 \mathrm{wt} . \%$ NR the value of $\varepsilon$ increases by 3.5 times. The values of the tensile strength and elasticity modulus (Figure $6 \mathrm{~b}, \mathrm{c}$ ) in PLA/NR fibers decrease with an increase of a NR content in non-woven fiber.

The PLA/NR system is a type of modification of a thermoplastic polymer by an elastomer. The mechanical properties of such composites do not change additively and are complex $[37,38]$. As a rule, the addition of rubber to the thermoplastic matrix leads to an increase in the elongation at break and a decrease in the tensile strength. The reduced PLA content in the composites and the poor interfacial adhesion between PLA and NR may be the reasons for the decreased the tensile strength and modulus. Increasing the rubber content to 50-70 wt.\% phase inversion may be observed [31,37]. 


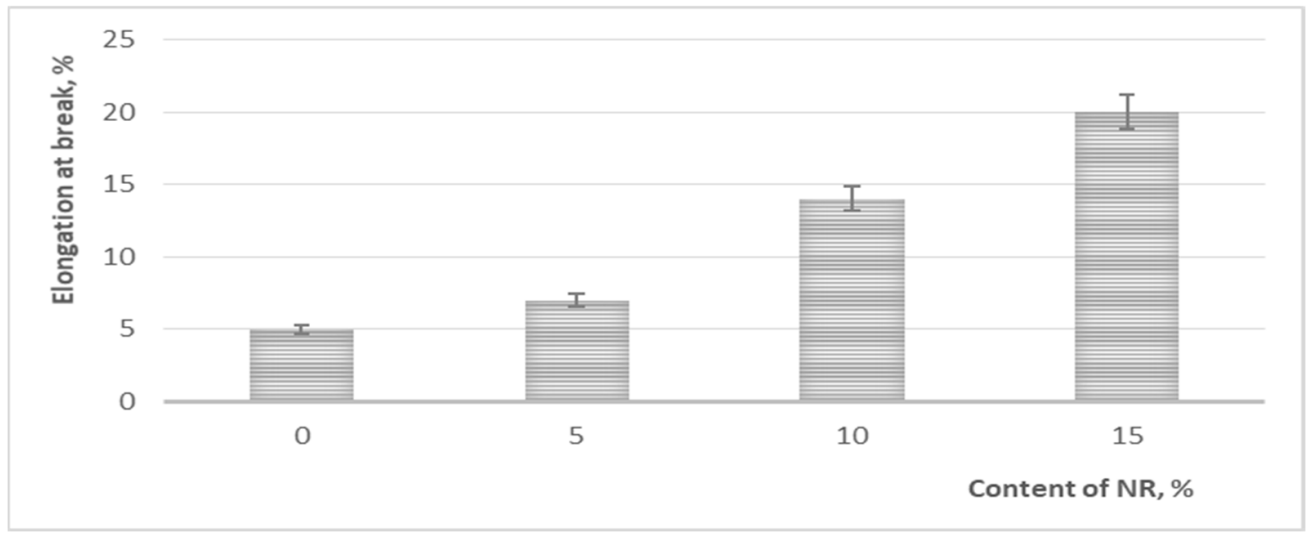

(a)

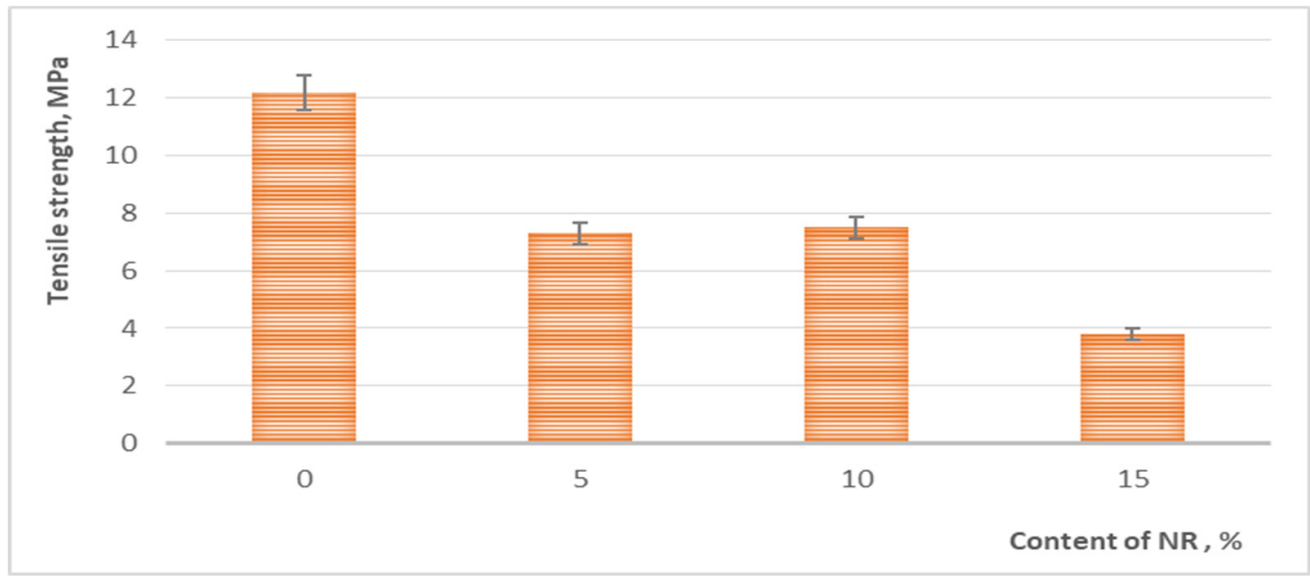

(b)

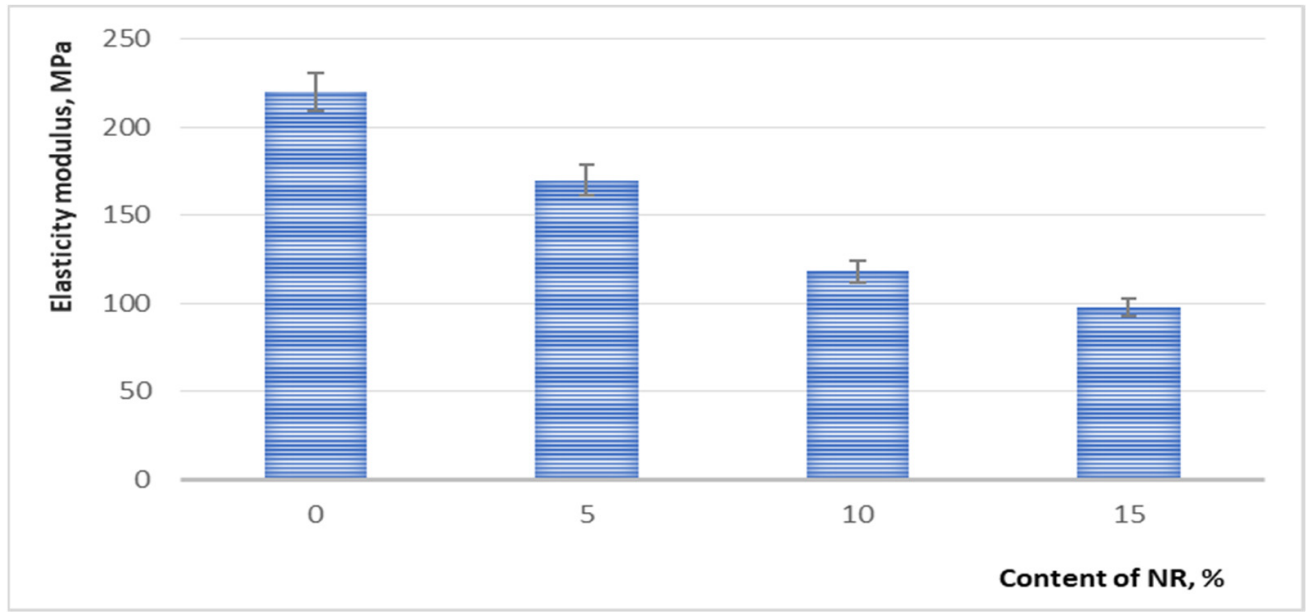

(c)

Figure 6. The dependence of the mechanical properties of PLA/NR fibers on the NR content: elongation at break, \% (a); tensile strength, $\mathrm{MPa}(\mathbf{b})$ and elasticity modulus, $\mathrm{MPa}(\mathbf{c})$.

\section{Discussion}

The morphology and diameter of the resultant fibers depend on many parameters. When obtaining fibrous materials from a polymer solution by evaporation of the solvent, the system passes the concentration interval from the initial concentration of the solution to $100 \%$ concentration. The process of evaporation of the volatile solvent is non-equilibrium, the viscosity of the system changes and a different thickness of the fiber is formed. Selecting the optimal parameters of the electrospinning process such as the electric voltage, the 
distance between the capillary, and the electrode-substrate deposition, allowed to obtain samples of non-woven fiber materials of satisfactory quality. As is known, the electric voltage must correspond to the viscosity and surface tension of the polymer solution to ensure the formation and maintenance of a solution jet from the capillary. The solvent also plays an important role. The selection of the solvent is one of the main factors influencing the electrospinning ability and fiber properties. It is known that electrical conductivity and surface tension (should be less $0.050 \mathrm{~N} / \mathrm{m}$ ) of the solvent impact on the fiber diameter and morphology. However, the choice of solvent or solvent mixture may be complicated for a polymer-polymer system therefore in this work chloroform was chosen with the electrical conductivity: $1.0 \times 10^{-4} \mu \mathrm{S} / \mathrm{cm}$ and the surface tension: $0.027 \mathrm{~N} / \mathrm{m}$.

The properties of a polymer blend depend on the properties of homopolymers, as well as on their macro- and microstructure, and their interface. Although PLA and NR are immiscible polymers, according to the Nishi-Wang equation some interaction between the PLA and NR phases occurs. As early as 1971, Helfand assumed that in the interphase region between immiscible polymers there is a certain degree of interpenetration, a limited diffusion of chain segments $[39,40]$. According to Kuleznev, the physical meaning of interfacial interaction is that the boundary macromolecules do not have the ability to occupy the same conformations as the macromolecules in the bulk of polymers [32]. The entropy of the boundary layers is lower. It is possible to transfer segments of macromolecules of a polymer into a layer of another one. The presence of interfacial interaction affects the thermophysical characteristics and various properties of the studied samples. The relationship between the dispersed phase (NR) and the dispersion medium (PLA) is important. The adding of an amorphous component (NR) into the matrix of a crystallizing polymer (PLA) will increase the proportion of the amorphous phase in the fiber composites, which in turn will necessarily affect the strength characteristics of the material. NR in the composites ensures the manifestation of forced elasticity, and the value of the elongation at break increases. The easier plastic deformation could be caused by different phenomena: cavitation (debonding of rubbery particles from PLA, cavitation inside the particles), or generation of crazes [38]. On the other hand, too large cavities could lead to premature fracture, which is not the case here.

The presented results support the necessity for the further investigation. It is planned to obtain PLA/NR fibers from a solution using a mixed-solvent system, as well as produce PLA/NR film samples, and compare the process of PLA crystallization in films with those in a fibrous material.

\section{Conclusions}

In the work PLA/NR fibers with an NR content of 0, 5, 10 and $15 \mathrm{wt} . \%$ were obtained by electrospinning, then their structural, thermal, dynamic and strength properties were studied. Due to the difference in the viscosity of polymers and the heterophase of fiber composites, a bead-string morphology is observed. Linear and surface densities do not depend much on the NR content in composites. According to the Nishi-Wang equation, some limited interface between PLA and NR was found. Adding of NR to the PLA matrix leads to an increase in the temperature of phase transitions $\left(T_{g}, T_{c c}, T_{m}\right)$ and a slight increase in the degree of crystallinity of the PLA. The EPR method shows a raising of mobility in the amorphous phase of fiber composites compared to pure PLA, and these changes are more noticeable when the experiment is conducted above the glass transition temperature of PLA. Mechanical properties depend on the composition of the PLA/NR fibers. Due to the forced elasticity, the elongation at break enhances, and since the amount of amorphous phase in fibrous samples increases, the tensile strength decreases with an increase of the NR content.

\section{Patents}

Tertyshnaya, Y.V.; Shibryaeva, L.S. Biodegradable fiber composite based on polylactide and its application for the plants growing, RU 2734883 C1, 2020, bul.30. 
Author Contributions: Conceptualization, Y.T.; methodology, Y.T. and S.K.; software, Y.T.; validation, Y.T. and M.M.; formal analysis, Y.T.; investigation, Y.T. and S.K.; resources, M.M. and A.D.; data curation, Y.T.; writing—original draft preparation, Y.T. and S.K.; writing—review and editing, Y.T.; visualization, Y.T. and S.K.; supervision, Y.T.; project administration, Y.T. and A.D.; funding acquisition, M.M. and A.D. All authors have read and agreed to the published version of the manuscript.

Funding: This research was funded by a grant of the Ministry of Science and Higher Education of the Russian Federation for large scientific project in priority areas of scientific and technological development (grant number 075-15-2020-774).

Institutional Review Board Statement: Not applicable.

Informed Consent Statement: Not applicable.

Data Availability Statement: The data presented in this study are available on request to the corresponding author.

Acknowledgments: The study was carried out using the devices of the Center of Shared Usage "New Materials and Technologies" (Emanuel Institute of Biochemical Physics, Russian Academy of Sciences, Moscow).

Conflicts of Interest: The authors declare no conflict of interest. The funders had no role in the design of the study; in the collection, analyses, or interpretation of data; in the writing of the manuscript, or in the decision to publish the results.

\section{References}

1. Auras, R.; Harte, B.; Selke, S. An overview of polylactides as packaging materials. Macromol. Biosci. 2004, 4, 835-864. [CrossRef]

2. Lee, S.; Wang, S. Biodegradable polymers/bamboo fiber biocomposite with biobased coupling agent. Compos. A. Appl. Sci. Manuf. 2006, 37, 80-91. [CrossRef]

3. Graupner, N.; Herrmann, A.S.; Mussig, J. Natural and man-made cellulose fibre-reinforced poly(lactic acid) (PLA) composites: An overview about mechanical characteristics and application areas. Compos. Part A 2009, 40, 810-821. [CrossRef]

4. Al-Enizi, A.; Zagho, M.; Elzatahry, A. Polymer-Based Electrospun Nanofibers for Biomedical Applications. Nanomaterials 2018, 8, 259. [CrossRef]

5. Agarwal, S.; Greiner, A.; Wendorff, J.H. Functional materials by electrospinning of polymers. Prog. Polym. Sci. 2013, 38, 963-991. [CrossRef]

6. Banica, F.G. Chemical Sensors and Biosensors: Fundamentals and Applications; Fogg, A.G., Ed.; John Wiley \& Sons: Chichester, UK, 2012; p. 541. [CrossRef]

7. Montazer, M.; Malekzadeh, S.B. Electrospun antibacterial nylon nanofibers through in situ synthesis of nanosilver: Preparation and characteristics. J. Polym. Res. 2012, 19, 9980. [CrossRef]

8. Du, B.; Chen, C.; Sun, Y.; Yu, M.; Liu, B.; Wangab, X.; Zhou, J. Lignin bio-oil-based electrospun nanofibers with high substitution ratio property for potential carbon nanofibers applications. Polym. Test. 2020, 89, 106591. [CrossRef]

9. Reneker, D.H.; Yarin, A.; Zussman, E.; Xu, H. Electrospinning of nanofibers from polymer solutions and melts. Adv. Appl. Mech. 2007, 41, 44-195. [CrossRef]

10. Wang, N.; Wang, X.; Ding, B.; Yu, J.; Sun, G. Tunable fabrication of threedimensional polyamide-66 nano-fiber/nets for high efficiency fine particulate filtration. J. Mater. Chem. 2012, 22, 1445-1452. [CrossRef]

11. Huang, L.; Arena, J.T.; Manickam, S.S.; Jiang, X.; Willis, B.G.; McCutcheon, J.R. Improved mechanical properties and hydrophilicity of electrospun nanofiber membranes for filtration applications by dopamine modification. J. Membr. Sci. 2014, 460, 241-249. [CrossRef]

12. Luo, Y.; Liu, X.; Huang, J. Nanofibrous rutile-titania/graphite composite derived from natural cellulose substance. J. Nanosci. Nanotechnol. 2013, 13, 582-588. [CrossRef] [PubMed]

13. Kaur, S.; Sundarrajan, S.; Rana, D.; Matsuura, T.; Ramakrishna, S. Influence of electrospun fiber size on the separation efficiency of thin film nanofiltration composite membrane. J. Membr. Sci. 2012, 392-393, 101-111. [CrossRef]

14. Riboldi, S.A.; Sampaolesi, M.; Neuenschwander, P.; Cossu, G.; Mantero, S. Electrospun degradable polyesterurethane membranes: Potential scaffolds for skeletal muscle tissue engineering. Biomaterials 2005, 26, 4606-4615. [CrossRef] [PubMed]

15. Mendes, S.S.; Filho, J.C.A.D.; Melo, A.R.A.; Nunes, L.C.S. Determination of thermal expansion coefficient of a monofilament polyamide fiber using digital image correlation. Polym. Test. 2020, 87, 106540. [CrossRef]

16. Jia, W.; Gong, R.H.; Hogg, P.J. Poly(lactic acid) fibre reinforced biodegradable composites. Compos. Part B 2014, 62, 104-112. [CrossRef]

17. Tertyshnaya, Y.V.; Lobanov, A.V.; Karpova, S.G.; Pantyukhov, P.V. Composites based on polylactide and manganese (III) tetraphenylporphyrin. Influence of concentration on the structure and properties. J. Molec. Liq. 2020, 302, 112176. [CrossRef]

18. Podzorova, M.V.; Tertyshnaya, Y.V. Degradation of Polylactide-Polyethylene Binary Blends in Soil. Rus. J. Appl. Chem. 2019, 92, 767-774. [CrossRef] 
19. Bogaert, J.C.; Coszac, P.P. Poly(lactic acid): A potential solution to plastic waste dilemma. Macromol. Symp. 2000, 153, 287-303. [CrossRef]

20. Casasola, R.; Thomas, N.L.; Trybala, A.; Georgiadou, S. Electrospun poly lactic acid (PLA) fibres: Effect of different solvent systems on fibre morphology and diameter. Polymer 2014, 55, 4728-4737. [CrossRef]

21. Jun, Z.; Hou, H.; Schaper, A.; Wendorff, J.H.; Greiner, A. Poly-L-lactidenanofibers by electrospinning-influence of solution viscosity and electrical conductivity on fiber diameter and fiber morphology. E-Polymers 2003, 3, 102-110. [CrossRef]

22. Nicosia, A.; Gieparda, W.; Foksowicz-Flaczyk, J.; Walentowska, J.; Wesolek, D.; Vazquez, B.; Prodi, F.; Belosi, F. Air filtration and antimicrobial capabilities of electrospun PLA/PHB containing ionic liquid. Separ. Purif. Technol. 2015, 154, 154-160. [CrossRef]

23. Tertyshnaya, Y.V.; Shibryaeva, L.S.; Levina, N.S. Biodestruction of Polylactide and Poly(3-Hydroxybutyrate) Non-Woven Materials by Micromycetes. Fibre Chem. 2020, 52, 43-47. [CrossRef]

24. Karpova, S.G.; Ol'khov, A.A.; Popov, A.A.; Zhul'kina, A.L.; Iordanskii, A.L. Analysis of the structure of ultrafine fibers based on poly(3-hydroxybutyrate) and polylactide: Effect of external factors. Polym. Sci. Ser. A 2019, 61, 480-490. [CrossRef]

25. Kurtycz, P.; Karwowska, E.; Ciach, T.; Olszyna, A.; Kunicki, A. Biodegradable polylactide (PLA) fiber mats containing $\mathrm{Al}_{2} \mathrm{O}_{3}-\mathrm{Ag}$ nanopowder prepared by electrospinning technique-Antibacterial properties. Fibers Polym. 2013, 14, 1248-1254. [CrossRef]

26. Kosowska, K.; Szatkowski, P. Influence of $\mathrm{ZnO}, \mathrm{SiO}_{2}$ and $\mathrm{TiO}_{2}$ on the aging process of PLA fibers produced by electrospinning method. J. Therm. Anal. Calorim. 2020, 140, 1769-1778. [CrossRef] [PubMed]

27. Tertyshnaya, Y.; Podzorova, M.; Moskovskiy, M. Impact of water and UV irradiation on nonwoven polylactide/natural rubber fiber. Polymers 2021, 13, 461. [CrossRef]

28. Sia, W.-L.; Yuana, W.-Q.; Lia, Y.-D.; Chenb, Y.-K.; Zengabc, J.-B. Tailoring toughness of fully biobased poly(lactic acid)/natural rubber blends through dynamic vulcanization. Polym. Test. 2018, 65, 249-255. [CrossRef]

29. Zhang, C.; Wang, W.; Huang, Y.; Pan, Y.; Jiang, L.; Dan, Y.; Luo, Y.; Peng, Z. Thermal, mechanical and rheological properties of polylactide toughened by expoxidized natural rubber. Mater. Des. 2013, 45, 198-205. [CrossRef]

30. Maroufkhani, M.; Katbab, A.; Zhang, J. Manipulation of the properties of PLA nanocomposites by controlling the distribution of nanoclay via varying the acrylonitrile content in NBR rubber. Polym. Test. 2018, 65, 313-321. [CrossRef]

31. Xu, C.; Yuan, D.; Fu, L.; Chen, Y. Physical blend of PLA/NR with co-continuous phase structure: Preparation, rheology property, mechanical properties and morphology. Polym. Test. 2014, 37, 94-101. [CrossRef]

32. Kuleznev, V.N. Polymer Blends; Chemistry: Moscow, Russia, 1980; pp. 125-172.

33. Pongtanayut, K.; Thongpin, C.; Santawitee, O. The effect of rubber on morphology, thermal properties and mechanical properties of PLA/NR and PLA/ENR blends. Energy Proced. 2013, 34, 888-897. [CrossRef]

34. Shah, A.A.; Hasan, F.; Shah, Z.; Kanwal, N.; Zeb, S. Biodegradation of natural and synthetic rubbers: A review. Int. Biodeterior. Biodegrad. 2013, 83, 145-157. [CrossRef]

35. Copinet, A.; Bertrand, C.; Govindin, S.; Coma, V.; Couturier, Y. Effects of ultraviolet light (315 nm), temperature and relative humidity on the degradation of polylactic acid plastic films. Chemospheres 2004, 55, 763-773. [CrossRef]

36. Nishi, T.; Wang, T.T. Melting Point Depression and Kinetic Effects of Cooling on Crystallization in Poly(vinylidene fluoride)Poly(methyl methacrylate) Mixtures. Macromolecules 1975, 8, 909-915. [CrossRef]

37. Tertyshnaya, Y.V.; Shibryaeva, L.S.; Ol'khov, A.A. The structure and properties of blends of poly(3-hydroxybutyrate) with an ethylene-propylene copolymer. Polym. Sci. Ser. B 2002, 44, 287-290.

38. Kowalczyk, M.; Piorkowska, E. Mechanisms of plastic deformation in biodegradable polylactide-poly(1,4- cis-isoprene) blends J. Appl. Polym. Sci. 2012, 124, 4579-4589. [CrossRef]

39. Helfand, E.; Tagami, K. Theory of the interface between immiscible polymers. J. Polym. Sci. Polym. Lett. 1971, 9, 741-746. [CrossRef]

40. Helfand, E. Theory of inhomogeneous polymers: Lattice model for polymer-polymer interfaces. J. Chem. Phys. 1975, 63, 2192-2198. [CrossRef] 